\title{
Management of Duane retraction syndrome with prismatic glasses
}

\author{
This article was published in the following Dove Press journal: \\ Clinical Ophthalmology \\ 12 April 2017 \\ Number of times this article has been viewed
}

\author{
Ebru Demet Aygit ${ }^{\prime}$ \\ Murat Kocamaz' \\ Asli Inal' \\ Korhan Fazil' \\ Osman Bulut Ocak' \\ Serpil Akar ${ }^{2}$ \\ Birsen Gokyigit \\ 'Strabismus Department, Beyoglu \\ Eye Training and Research Hospital, \\ Istanbul, Turkey; ${ }^{2}$ Ophthalmology \\ Department, Medicine Faculty, \\ Baskent University, Istanbul, Turkey
}

Purpose: To report the results of using prismatic glasses for Duane retraction syndrome (DRS). Methods: Data were obtained from the records of patients who were evaluated during the year 2000 in the Strabismus Unit of the Beyoglu Eye Training and Research Hospital. The average follow-up was $12.2 \pm 17.7$ months. In all cases, 2 main variables were evaluated: horizontal deviation in the primary position and face turn. Prismatic glasses were provided to patients according to the degree of shift in the primary position.

Results: The mean age of patients was 11.2 years. An analysis was performed on the data collected from 12 cases; 7 patients were females (58.3\%) and 5 were males (41.7\%), with $11(91.7 \%)$ cases being of type I DRS. All 12 patients had abnormal head posture (face turn) and an angle of mean deviation equaling 10 PD (prism dioptri).

Conclusion: Treatment was individualized on a case-by-case basis. Prismatic glasses are useful for eliminating abnormal head posture and ocular misalignment in selected cases.

Keywords: Duane, prismatic glasses, abnormal head posture

\section{Introduction}

Duane retraction syndrome (DRS) was recognized by Stilling in 1887 and Turk in 1896. Alexander Duane's publication of Duane retraction syndrome (DRS) was in 1905. As a result, DRS is also referred to in the literature as Stilling-Turk-Duane Syndrome. ${ }^{1}$ DRS is characterized by the following main features: 1) complete or partial absence of abduction of the affected eye; 2) partial, or rarely complete, deficiency of adduction of the affected eye; and 3 ) retraction of the affected eye into the orbit on adduction. More recently, these characteristics have been named as congenital cranial dysinnervation disorders (CCDDs) in the literature.

DRS is a paradoxic innervation of the lateral rectus (LR) during adduction. It is usually diagnosed early in childhood. Electromyography (EMG) studies of patients with DRS have shown that there is gross abnormality of the innervational pattern in this condition. Using EMG, Huber ${ }^{2}$ classified DRS into 3 types:

- Type I: Abduction restriction, normal or restricted adduction with associated retraction of the globe, and widening of the palpebral fissure on attempted abduction.

- Type II: Restricted adduction and abduction and retraction of the globe on adduction, frequently associated with exotropia.

- Type III: Severe restriction of both abduction and adduction, with either minimal esotropia orexotropia or near orthophoria and retraction on adduction and widening of the palpebral fissure on abduction.

The aims of treatment for DRS are to achieve eye alignment in the primary position, to eliminate abnormal head posture (AHP), and to prevent amblyopia. Some patients 
do not require surgical correction because they have neither great deviation nor face turn. In this study, we describe the results of our medical treatment of DRS patients.

\section{Methods}

This study was retrospective and observational. All charts of the patients who were seen at our Hospital's Strabismus Department between 2000 and 2015 and who were given a diagnosis of DRS were reviewed. Written informed consent was obtained from all patients or patients' families. This study was in compliance with the principles of the Declaration of Helsinki and was conducted in accordance with Beyoglu Göz Training and Research Hospital Institutional Review Board regulations.

Patients with DRS who underwent medical treatment with prismatic glasses and who had a minimum follow-up of 3 months were included in the study. Patients were excluded if they had $<3$ months of follow-up.

All patients underwent complete ophthalmologic and orthoptic examinations. The following information was recorded: age, sex, family history of strabismus, systemic disease, refractive status, presence or absence of amblyopia, AHP, and history of strabismus surgery.

Ocular alignment was graded as follows: orthotropia, with no movements noted on cover-uncover test; small-angle eso- or exodeviation, with phoria or tropia within $10 \mathrm{PD}$ (prism dioptri) and significant eso- or exotropia, with deviation $>10$ PD. Ocular misalignment data were obtained using the prism cover test and Krimsky test. This management has been suggested for patients who do not want botulinum toxin A or surgery, in addition to having a small deviation and AHP.

Ductions were graded on a scale from 0 (full duction) to -4 (indicating an inability to move the eye past the midline). Head-turn measurements were recorded and evaluated at distance and at near fixation with best optical corrections. An estimation of AHP was arrived at by an orthoptic method (the nose being the focus), photographed, and the patient's distance- and near-reading positions observed.

The head turn is usually toward the affected eye for type 1 patients. Noses were used to evaluate the AHP, and patients were separated into 2 groups with AHP, namely, those with $<10^{\circ}$ and $>10^{\circ}$ face turn. Palpebral fissures were investigated for retraction in adduction in all patients. At the same time, the upshoot or downshoot of the affected eye was assessed in adduction.
Stereoacuity for near vision was recorded using the Titmus Fly Stereo Test for all patients. All patients were treated with appropriate prismatic prescriptions and evaluated at 1 month and 3 months.

Data were analyzed using Minitab Statistical Software, release 20 (Minitab Inc, State College, PA, USA). A paired $t$-test was used for analysis. Statistical significance was defined at a level of $P<0.05$.

\section{Results}

A total of 638 records of strabismus patients diagnosed with DRS were available for review. Of these, 12 patients met the study inclusion criteria. The study group consisted of $7(58.3 \%)$ girls and $5(41.7 \%)$ boys. The mean age at presentation was 11.2 years (range: 5-20 years). The left eye was involved in 7 patients $(66.7 \%)$ and for 1 patient, the condition was bilateral (8.3\%). Type 1 DRS was identified in $11(91.7 \%)$ patients.

All patients had hyperopia and only 1 had amblyopia. AHP was evaluated; $8(66.7 \%)$ patients had $<10^{\circ}, 4(33.3 \%)$ patients had $>10^{\circ}$ face turn. The mean follow-up period was $12.2 \pm 17.7$ months (range: 3-48 months). Orthophoria was seen in $10(88.3 \%)$ patients. Esotropia was measured in $2(16.7 \%)$ patients at near and distance fixation upon admission. The mean esodeviations were $12 \mathrm{PD}$ and $10 \mathrm{PD}$ at near and distance fixation, respectively. All our patients had AHP (face turn). At the same time, our patient's palpebral fissures were normal and equal on both sides in the primary position. Upshoot or downshoot was not observed.

At the patients' 3-month clinical examinations, ocular misalignment in the primary position was found to have been eliminated with prismatic glasses in 12 patients. AHP disappeared completely in 5 patients, and had reduced in 7 patients. The patients' stereoacuity was reasonably good.

This study reports the results of medical management using prismatic glasses to treat patients with DRS.

\section{Discussion}

DRS is a congenital disease that may affect the eyes unilaterally or bilaterally. The prevalance is $2 \%-4 \%$ among all patients with strabismus. In the general population, the prevalence of DRS is about $1 / 1,000 .{ }^{1}$ DRS prevalence was $1.2 \%$ in the strabismus patients included in our study. It occurs sporadically in $90 \%$ of cases and is inherited in a small percentage as an autosomal dominant disorder. ${ }^{3-6}$ Bilateral cases represent $15 \%-20 \%$ of all cases of DRS. This study found $8.3 \%$ of DRS patients with bilateral involvement. ${ }^{4,6-8}$ 
DRS patients should receive individualized treatment according to the clinical manifestations observed. The aims of management in DRS include the elimination or improvement of abnormal head position (face turn), the treatment of significant or slight ocular misalignment, the reduction of severe globe retraction, and the improvement of upshoots and downshoots.

Refractive error must be corrected in patients with DRS as the first step in medical treatment. The prevalence of amblyopia in DRS patients ranges from 3\% to $48 \%$ in the literature. ${ }^{4,9,10}$ Amblyopia was found in only 1 patient (8.3\%) in our study and we advised this patient occlusion therapy. O'Malley et $\mathrm{al}^{11}$ and Mohan et $\mathrm{al}^{12}$ reported amblyopia in $14 \%$ of their study group. Corrective lenses or contact lenses are used to correct refractive errors, and standard occlusion therapy is used to treat amblyopia. ${ }^{13}$

The correction of hypermetropic refractive error in children may reduce the angle of strabismus and DRS symptoms. Kekunnaya et $\mathrm{al}^{14}$ demonstrated that, in 1 case, face turn and esotropia in the primary position were eliminated with corrective lenses alone.

Park et $\mathrm{al}^{15}$ found in their study that orthotropia occurred in the majority (59\%), followed by exotropia in $23.1 \%$, and esotropia in $17.9 \%$. Similarly, Isenberg and Urist's study reported that $28 \%$ were esotropic, $29 \%$ were exotropic, and $43 \%$ were orthotropic. Orthotropia was the most common primary position, and esotropia was found in only $2(16.7 \%)$ patients in our study. Our patients with esotropia had 12 PD deviation in near vision and $10 \mathrm{PD}$ in distance vision.

Strabismus can be called comitant or incomitant strabismus based on whether deviation is equal in all positions of gaze or varies with the direction of gaze. ${ }^{16}$ Concomitant strabismus includes conditions such as palsy of the 4th and 6 th cranial nerves, DRS, Brown syndrome, inferior oblique overaction, as well as "A" and "V" patterns. Orthoptic vision therapy is a treatment alternative in DRS patients. The goal of the orthoptic treatment is the strongest possible fusion in primary gaze, as well as maximization of both monocular and binocular accommodative skills, including amplitude and flexibility.

A major finding of this study was that prismatic lenses may improve AHP and ocular misalignment, especially in cases with small deviation and AHP. Our study showed that prismatic glasses improved AHP completely in $41.6 \%$ of cases and reduced it to an acceptable level in 58.3\% of the selected DRS patients. At the same time, we obtained improvement in ocular misalignment in the primary position.
Therefore, prismatic improvement treatment is an alternative to surgery in these cases.

A surgical approach was required for a DRS patient with prominent ocular misalignment, marked AHP, cosmetically unacceptable upshoots and downshoot, and severe globe retraction on adduction. However, there is a possibility of treatment with prismatic glasses in selected patients if deviation is within $10 \mathrm{PD}$ and AHP is $10^{\circ}$.

The total DRS patient sample size is the main strength of this study. However, the study group size is limited because only DRS patients with face turn $<10^{\circ}$, deviation $\leq 12 \mathrm{PD}$, and followed for at least 3 months in our clinic, were included in the study. Further study with wider case series and longer follow-up should be undertaken to support the results of this study.

\section{Conclusion}

To our knowledge, this study is the first study with the aim of presenting the treatment results of prismatic eyeglasses in patients with DRS.

\section{Disclosure}

The authors report no conflicts of interest in this work. The authors alone are responsible for the content and writing of this paper.

\section{References}

1. Andali D, Javadzadeh A. Lateral rectus muscle disinsertion and reattachment to the lateral orbital wall in exotropic Duane syndrome: a case report. J Med Case Reports. 2008;2:253.

2. Huber A. Electrophysiology of the retraction syndromes. $\mathrm{Br} J$ Ophthalmol. 1974;58(3):293-300.

3. Yüksel D, Orban de Xivry JJ, Lefèvre P. Review of the major findings about Duane retraction syndrome (DRS) leading to an updated form of classification. Vision Res. 2010;50(23):2334-2347.

4. DeRespinis PA, Caputo AR, Wagner RS, Guo S. Duane's retraction syndrome. Surv Ophthalmol. 1993;38(3):257-288.

5. Gurwood AS, Terrigno CA. Duane's retraction syndrome: literature review. Optometry. 2000;71:722-726.

6. Appukuttan B, Gillanders E, Juo SH, et al. Localization of a gene for Duane retraction syndrome to chromosome 2q31. Am J Hum Genet. 1999;65(6):1639-1646.

7. Murillo-Correa CE, Kon-Jara V, Engle EC, Zenteno JC. Clinical features associated with an I126M $\alpha 2$-chimaerin mutation in a family with autosomal dominant Duane retraction syndrome. J AAPOS. 2009; 13(3):245-248.

8. Khan AO, Oystreck D. Clinical characteristics of bilateral Duane syndrome. J AAPOS. 2006;10(3):198-201.

9. Chung M, Stout T, Borchert MS. Clinical diversity of hereditary Duane's retraction syndrome. Ophthalmology. 2000;107:500-503.

10. Chua B, Johnson K, Donaldson C, Martin F. Management of Duane retraction syndrome. J Pediatr Ophthalmol Strabismus. 2005;42: 13-17.

11. O'Malley ER, Helveston EM, Ellis FD. Duane's retraction syndromeplus. J Pediatr Ophthalmol Strabismus. 1982;19(3):161-165. 
12. Mohan K, Sharma A, Pandav SS. Differences in epidemiological and clinical characteristics between various types of Duane retraction syndrome in 331 patients. J AAPOS. 2008;12(6):576-580.

13. Andrews CV, Hunter DG, Engle EC [webpage on the Internet]. Duane syndrome. In: GeneReviews; 2012. Available from: http://www.ncbi. nlm.nih.gov/books/NBK1190/. Accessed October 8, 2016.

14. Kekunnaya R, Kraft S, Rao VB, Velez FG, Sachdeva V, Hunter DG. Surgical management of strabismus in Duane retraction syndrome. J AAPOS. 2015;19(1):63-69.
15. Park WH, Son DH, Yoon SW, Baek SH, Kong SM. The clinical features of Korean patients with Duane's retraction syndrome. Korean J Ophthalmol. 2005;19(2):132-135.

16. Ansons AM, Davis H, editors. Diagnosis and management of ocular motility disorders, 3rd edition. Oxford: Wiley-Blackwell Science; 2001.

\section{Publish your work in this journal}

Clinical Ophthalmology is an international, peer-reviewed journal covering all subspecialties within ophthalmology. Key topics include: Optometry; Visual science; Pharmacology and drug therapy in eye diseases; Basic Sciences; Primary and Secondary eye care; Patient Safety and Quality of Care Improvements. This journal is indexed on

\section{Dovepress}

PubMed Central and CAS, and is the official journal of The Society of Clinical Ophthalmology (SCO). The manuscript management system is completely online and includes a very quick and fair peer-review system, which is all easy to use. Visit http://www.dovepress.com/ testimonials.php to read real quotes from published authors. 